\title{
A presença de Nietzsche no percurso intelectual de Horkheimer
}

The presence of Nietzsche in the intellectual path of Horkheimer

\author{
Eduardo Brandão \\ edubrand@usp.br \\ (Universidade de São Paulo, São Paulo, Brasil)
}

\begin{abstract}
Resumo: 0 presente artigo busca indicar as transformações na abordagem da filosofia de Nietzsche ao longo da produção intelectual de Horkheimer até o início da década de 1940. Nesse percurso, é possível perceber que o teor das análises de Nietzsche alterase também na medida em que sua filosofia é contraposta ao marxismo, que nesse movimento surge com perda significativa de sua capacidade explicativa da realidade.
\end{abstract}

Palavras-chave: Horkheimer; Nietzsche; Civilização.

\begin{abstract}
The present article seeks to indicate the transformations in the approach of Nietzsche's philosophy throughout the intellectual production of Horkheimer until the beginning of the 1940s. In this way, it is possible to perceive that the content of the analyzes of Nietzsche also changes in the measure in which his philosophy is opposed to the Marxism, that in this movement arises with significant loss of its capacity of explanation of the reality.
\end{abstract}

Keywords: Horkheimer; Nietzsche; Civilization.

DOI: http://dx.doi.org/10.11606/issn.2318-9800.v22i2p39-48

Comentando o texto "Estado autoritário" de Horkheimer, escreve Habermas em Observações sobre o desenvolvimento da obra de Max Horkheimer:

O local no qual este ensaio foi publicado não é de modo algum acidental; Horkheimer distancia-se da concepção histórica materialista e evolui na linha de Benjamin. Ele agora considera possível que o aumento das forças produtivas possa tanto vir a produzir o socialismo como liquidá-lo. O que uma vez foi chamado de "socialismo" parece ter perdido toda relação interna com o progresso histórico. A esperança revolucionária não possui mais nenhuma ancoragem no mundo, ela é utópica no mau sentido; seja como for, ficou sem lugar. A esperança numa tensão dialética intrínseca ao processo histórico esvaiu-se. Se agora só pode ocorrer de se saltar para fora do contínuo da história, é porque as tendências históricas observáveis perderam todo interesse mais sério. O que ainda compensa estudar são somente os invariantes responsáveis pela continuidade da desgraça e da opressão. 0 que demonstra interesse é unicamente a estrutura de uma dominação que tomou conta do progresso na forma da razão instrumental. Não mais Marx indica o caminho, mas Nietzsche. Não é a teoria histórico-social que deve explicar "porque a humanidade, ao invés de adentrar num estado verdadeiramente humano, afunda num novo tipo de barbárie", mas uma 
crítica radical da razão que denuncia o íntimo parentesco entre razão e dominação. Este já era o tema do tratado "Razão e Autoconservação", no qual Horkheimer reveste as velhas ideias de uma nova e característica roupagem [Wendung] (Habermas, 2007, p.280).

A intenção de meu artigo é, a partir dessa citação, recolher elementos no itinerário intelectual de Horkheimer que indiquem que esta posição de Nietzsche, delineada por Habermas nesse momento da reflexão de Horkheimer (por volta dos anos 1940), não é de modo algum abrupta ou externa àquilo que se pode encontrar em seus textos, e é um sintoma - talvez o mais explícito - dessa mudança de rumo [Wendung] a que se refere Habermas na passagem acima. É reconhecida entre alguns comentadores - por exemplo, Norberth Rath, (Zur Nietzsche-Rezeption Horkheimer und Adornos, in Vierzig Jahren Flaschenpost: Dialetik der Aufklärung 1947 bis 1987) a mudança de posição de Horkheimer no que diz respeito à sua leitura de Nietzsche. Mas essa menção a Rath põe em cena os limites do que será tratado em meu texto. Menciono apenas três aspectos desse recorte: 1) A importância da colaboração com Adorno para a interpretação de Horkheimer sobre Nietzsche não será agora considerada; 2) Dentro dessa colaboração, o papel que desempenha a presença de Walter Benjamin também não será explorado; e por fim 3) A situação da interpretação de Nietzsche no contexto dos trabalhos do Instituto de Pesquisa Social não será levada em conta. Há em relação a este último ponto uma presença marcante de Nietzsche nas páginas da Zeitschrift für Sozialforschung (cf. Chaves, 2010). 0 segundo ponto também surge, por exemplo, na correspondência entre Horkheimer e Adorno, ${ }^{1}$ e ronda um texto como $O$ fim da razão cuja versão alemã, Vernunft und Selbsterhaltung (Razão e autoconservação), como lembra Habermas em Observações sobre o desenvolvimento da obra de Max Horkheimer, surge (ao lado de Estado autoritário) numa coletânea de textos em homenagem a Walter Benjamin. ${ }^{2} \mathrm{E}$ é o próprio Habermas que nota, como vimos, a proximidade das ideias de Horkheimer, neste momento de sua produção intelectual, com o pensamento de Benjamin - cujas relações com Nietzsche são reconhecidas - e a centralidade da presença de Adorno neste ponto:

Quando Adorno veio a colaborar na redação da versão para impressão de "Razão e Autoconservação", foi Horkheimer que, a partir de um impulso próprio resultante de seu desenvolvimento pessoal, dispôs-se a um trabalho em conjunto com Adorno -

1 Cf. Wiggershaus, 2002, p.193: "E Horkheimer, que havia novamente reencontrado Benjamin em Paris, em setembro de 1937 durante uma de suas viagens à Europa, escreveu em seguida a Adorno: 'Algumas horas com Benjamin constituem os mais agradáveis momentos. De todos é ele, de longe, o mais próximo de nós' (carta de Horkheimer a Adorno, de 13 de outubro de 1937)". Cf. Horkheimer. M., Gesammelte Schriften, Band 16, p.240.

2 Cf. Horkeimer, M., Gesammelte Schriften, Band 5, p.460; Arato e Gebhardt (1993), p.95. A coletânea em homenagem a Benjamin, Walter Benjamin zum Gedächtnis, não chegou a ser publicada, mas apenas impressa numa edição privada. 
isso atestam ambos no ensaio dedicado a Benjamin. Adorno tinha desde o princípio incorporado motivos benjaminianos, que, para Horkheimer, só se tornaram virulentos no começo dos anos 1940, sob pressão da experiência política (Habermas, 2007, p.282).

Essas indicações são suficientes para estabelecer o âmbito de minha análise, que se limitará a selecionar algumas passagens de textos de Horkheimer produzidos entre 1920 e o início de 1940 para refletir sobre sua mudança de perspectiva em relação ao pensamento de Nietzsche. Nesse sentido, farei um percurso que levará a dois textos: O fim da razão (de Horkheimer, escrito em 1941) e um protocolo de discussão de 14 de julho de 1942 no Instituto de pesquisas sociais. ${ }^{3}$

A primeira passagem que eu gostaria de destacar se encontra em Dämmerung, escrito entre 1926 a 1931, intitulada Nietzsche e o proletariado.

Nietzsche ridicularizou a cristandade, porque seu ideal veio da falta de poder. (...) Ele desdenha da massa, mas quer conservá-la como massa. Ele quer conservar fraqueza, covardia, obediência, para conseguir a cultivação de seu espaço utópico de aristocratas. Aos quais a toga deve ser feita pelos outros, e com isso eles não passam por vagabundos, pois se não pudessem viver do suor das massas, eles mesmos precisariam estar nas máquinas. (...) Na verdade, Nietzsche está extremamente satisfeito porque há a massa, em nenhum lugar ele aparece como um opositor efetivo do sistema, que se baseia em exploração e miséria. Por isso, segundo ele é tanto certo quanto útil que as disposições dos homens se atrofiem sob condições miseráveis, a tal ponto que ele transpõe seu desenvolvimento para o além-do-homem. As metas de Nietzsche não são as do proletariado. Mas pode-se observar que a Moral, que se sugere a ele como algo digestivo (ou contratual), é apenas mistificação segundo este filósofo das classes dominantes. Ele mesmo grava na memória das massas que apenas o medo as impede de quebrar esse aparato. Se elas entenderem isso efetivamente, até mesmo Nietzsche pode contribuir para isso, transformar a rebelião dos escravos na Moral na práxis proletária (Horkheimer, (1987-1996), Band 2, p.338).

O tom crítico é evidente. Mas já se anuncia aqui uma ideia sobre Nietzsche que, nos próximos textos de Horkheimer, estará a meu ver bastante presente na medida em que estamos na fase, digamos, mais marxista de Horkheimer: Nietzsche é um filósofo da burguesia, mas com o qual se tem muito a aprender sobre o lugar de onde a burguesia fala. Esta é uma apreciação cuja estrutura encontramos em outros textos produzidos por Horkheimer no início de seu percurso: Nietzsche, ao mesmo tempo em que deve ser visto sob um olhar crítico, tem sempre algo a ensinar. 0 tipo de crítica que se endereça a Nietzsche se altera (por exemplo, na medida em que Horkheimer está mais ou menos próximo do marxismo) e aquilo que se aprende a partir dele também muda, no mesmo movimento. Esse olhar que cruza crítica

3 Cf. The end of reason in Arato e Gebhardt (1993), pp.26 a 48; Vernunft und Selbsterhaltung in Horkheimer, M. Gesammelte Schriften, Band 5, pp.320 a 350. O protocolo de discussão encontrase no volume 12 dos Gesammelte Schriften de Horkheimer, pp.563 a 570. Há uma tradução inglesa deste protocolo feita por Michael Winkler e Richard Wolin e publicada em Constellations, volume 8, n. 1, 2001. 
e aprendizado - amálgama que, digamos, controla a acidez dos comentários de Horkheimer sobre Nietzsche - atravessa seus textos até, pelo menos, a Dialética do esclarecimento.

Como exemplo, tomemos esta passagem em Da discussão do Racionalismo na filosofia contemporânea (1934).

A tendência contra o racionalismo na literatura e na pintura impressionistas, bem como a filosofia de Nietzsche e de Bergson já permitem, de fato, reconhecer a insegurança da burguesia na sua tradição humanística, porém exprimem, ao mesmo tempo, o protesto contra o aprisionamento da vida individual pela crescente concentração do capital (Horkheimer, 2006, p.99).

Ou essa, no mesmo texto: “O irracionalismo filosófico de Nietzsche e de Bergson chamara a atenção das próprias camadas dominantes para seu empobrecimento interior condicionado pela economia, ao lembrar-lhes suas próprias possibilidades, as possibilidades da 'vida'” (Horkheimer, 2006, p.124). Ou seja, na obra de Nietzsche irrompe a contradição inerente ao modo burguês de organização da economia: eis um filósofo burguês que mostra exemplarmente o lugar onde a burguesia viceja e adoece ao mesmo tempo. Mas Nietzsche também aparece com um interlocutor de quem se tem algo a aprender, num sentido mais amplo. Por exemplo, nesta outra passagem ainda no mesmo texto de Horkheimer podemos ler: "Todavia, a análise nietzschiana da revalorização, apesar de suas deficiências, é significativa também para estas novas funções sociais " (Horkheimer, 2006, p.131). Ou seja, Nietzsche aparece num contexto de referências que mesclam críticas (sejam pela sua orientação ideológica sejam pelos limites de sua abordagem) e, digamos, elogios - na medida em que se mostra um autor com algo a contribuir na análise de uma série de temas filosóficos e mesmo sociais. Exemplar, nesse sentido, é esta passagem de Sobre o problema da verdade (1935):

Enquanto a irreligiosidade que caracteriza a ciência natural e a técnica modernas, estas realizações especificamente burguesas, não encontrou um lugar correspondente na consciência geral e não foram resolvidos os conflitos ligados a isto, permaneceu inerente à intelectualidade oficial um traço de hipocrisia e de indulgência para com certos tipos de erros e injustiças que afinal se estendeu por sobre a vida cultural de povos inteiros. 0 único grande espírito que, em vista da maligna condensação desta névoa desde os meados do último século, conseguiu libertar-se das ilusões e obter a visão do que é possível a partir das posições da grande burguesia, foi Nietzsche. Decerto, deve-lhe ter escapado que a seriedade intelectual que the importava não se coadunava com este ponto de vista social. Nem no caráter individual nem no nacional se encontra a causa da sujeira que ele combateu, mas na estrutura da totalidade social que em si contém ambas. Ele, como filósofo tipicamente burguês, ao fazer da psicologia, embora a mais profunda que existe até hoje, a ciência fundamental da história, desconheceu a origem da decadência espiritual e o caminho para sair dela e, por isso, o destino que tomou a sua obra ("Quem dos meus amigos teria visto naquilo mais do que uma pretensão indevida, felizmente de todo inconsequente" [citação de Ecce Homo, Caso Wagner §4 - Nietzsche não está a falar de sua obra inteira, mas de Assim falou Zaratustra]) tem sua razão necessária (Horkheimer, 2006 p.173). 
A ideia aqui me parece clara: a agudeza da análise de Nietzsche, o crítico burguês da burguesia só não foi maior, e assim sua obra não logrou maior êxito, pelo fato dele ser, justamente, um crítico burguês. Bastará esta orientação marxista de interpretação perder sua força para que Horkheimer se aproxime mais de Nietzsche, na medida em percebe que a análise nietzschiana da burguesia tem a mesma origem que sua censura ao socialismo, ambas inserindo-se numa crítica maior à civilização e à cultura.

Em 1936, em Autoridade e família (não por acaso), o tom com Nietzsche assume outros matizes (sem que Horkheimer deixe, por isso, de tecer críticas ao filósofo). Esse limite burguês de Nietzsche parece cada vez menos problemático - ou é no mínimo menos lembrado. Tomemos algumas passagens do texto:

O próprio exercício da ciência, em muitos casos, é motivado pela necessidade de encontrar uma instrução firme como meta e caminho, de descobrir um sentido e finalidade da ação. “Pensais que procurais a verdade?”, lê-se num trecho de Nietzsche. "Procurais um líder e quereis deixar-vos ser comandados com prazer'”. Contudo, o impulso de submissão não é uma grandeza eterna, mas um fenômeno originado essencialmente na família unicelular burguesa (Horkheimer, 2006, p.223).

Note-se que aqui a análise de Nietzsche é invocada contra a burguesia, sem que se relembre o lugar burguês de que Nietzsche falaria; em outro trecho, um fragmento póstumo de Nietzsche é usado para endossar um pensamento de Horkheimer (algo que ocorre em outros momentos do texto):

Com o desemprego, que não só torna incerto o trabalho livre, mas também o converte, afinal, num privilégio de grupos de população relativamente limitados e cuidadosamente escolhidos, torna mais raro, sem dúvida, este tipo de família progressista; a desmoralização total, a submissão a qualquer amo e falta de oportunidade de trabalho produtivo desfizeram, em larga escala, as iniciativas de novos tipos de educação. "A estima da autoridade aumenta na proporção da diminuição de forças criativas" [Citação de um fragmento póstumo de Nietzsche. Cf. Nietzsche, (1988), Band 10, p.285, fragmento 7[128]]" (Horkheimer, 2006, p.233).

Mas outra passagem de Autoridade e família é exemplar para ilustrar um aspecto central desse novo tom da leitura de Nietzsche:

Embora, por exemplo, o conhecimento possa entrar não só como fator importante na evolução e na estabilidade de uma sociedade, mas esteja até diretamente na raiz da socialização em geral, como afirma, além de algumas teorias do esclarecimento, também um psicólogo como Freud, no entanto todo o aparelho psíquico dos membros de uma sociedade de classes, a não ser que pertençam àquele núcleo de privilegiados, constitui, em larga escala, apenas a interiorização ou, pelo menos, a racionalização e complementação da violência física. A chamada natureza social, o integrar-se numa ordem estabelecida, mesmo que se justifique pragmática, moral ou religiosamente, origina-se em essência da recordação de atos de coação pelos quais os homens se tornam "sociáveis", civilizados e que ainda hoje os ameaçam se por acaso se tornarem por demais esquecidos. Foi sobretudo Nietzsche quem descobriu estas relações (Horkheimer, 2006, p.182). 
Eis que começa a surgir aqui, para muito além do filósofo burguês, o crítico da civilização e da cultura. E Horkheimer reconhece o valor da análise nietzschiana, que põe em primeiro plano o vínculo entre ambas e dominação. Este ponto é central, e vai eclodir, da forma mais intensa e acabada, na Dialética do esclarecimento, no excurso II (Juliette ou esclarecimento e moral). Mas outra passagem do mesmo Autoridade e família sugere que essa percepção de Horkheimer seria, aos olhos de Nietzsche, ainda parcial.

O traço característico dessa ordem, de que o trabalho se cumpre sob a direção de autoridades, que o são por causa de seus bens ou de outros acasos da sorte e podem reportar-se cada vez menos a outros do que ao fato de que as coisas, são como são, este traço dá o tom a tudo o que hoje se chama razão, moral, honra e grandeza. Mesmo o mérito verdadeiro, o conhecimento extraordinário e capacidade prática são atingidos por isso e desfigurados. Eles parecem bem menos o bem da comunidade do que o direito legal ao poder e à exploração; quanto ao respeito que recebem, nota-se que ele também é prestado igualmente à conta bancária, cujo proprietário ele ainda enaltece retroativamente, quando não se detém também diante do gênio e reveste os dois com o mesmo brilho. Ninguém viu com mais clareza que Nietzsche a concatenação desta condição geral com a filosofia idealista (Horkheimer, 2006, p.211).

Horkheimer prossegue com uma citação das Segundas considerações extemporâneas; ora, basta avançar um pouco na obra de Nietzsche (para além das Considerações extemporâneas, considerando a cronologia de seus textos) para perceber que a crítica que Nietzsche endereça à filosofia idealista (no que diz respeito ao vínculo estreito entre racionalidade, moralidade e dominação ou domesticação) é uma crítica ao próprio mecanismo da civilização. Ou, em outros termos, do esclarecimento. Mas em 1936 o consórcio entre crítica da economia política e racionalidade ainda está suficientemente robusto para que esta leitura mais ampla da filosofia de Nietzsche não precise de um lugar nas análises de Horkheimer, pois aquele consórcio (ou talvez, melhor dizendo, simbiose) ainda promete uma saída viável (mesmo que trabalhosa) para uma sociedade emancipada. Basta ir a um texto como Teoria tradicional e teoria crítica (1937) para perceber isso e entender porque, mesmo vista a partir de um ponto de vista mais favorável, a filosofia de Nietzsche ainda pode ser medida a partir do marxismo.

Numa resenha sobre o livro de Jaspers sobre Nietzsche (de 1936), publicada em 1937 na Revista de pesquisa social do instituto, a aproximação com Nietzsche mostra esta faceta. Ernani Chaves, num artigo intitulado "O Nietzsche francês nas páginas da Zetischrift für Sozialforschung” trata disso. Escreve Chaves:

Contra Jaspers, Horkheimer começa destacando a radicalidade do pensamento de Nietzsche, colocando-o em relação com Marx e Freud. Diz ele que "Nietzsche analisou o espírito objetivo de sua época, a constituição psíquica da burguesia", numa espécie de antecipação, diríamos nós, das análises freudianas em seus textos 
sobre a cultura, algo que não escapou a Horkheimer. Por outro lado, não se poderia deixar de reconhecer, afirma Horkheimer, os elementos utópicos - e por isso mesmo emancipatórios - contidos na concepção do Além-do-homem. O problema, segundo Horkheimer, é que Nietzsche não conheceu Marx, mas apenas os social-democratas. A consequência disso é dupla: a primeira é que Nietzsche não pode conceber a meta do Além-do-homem como sendo a "sociedade sem classes", um conceito que aos poucos se perde na Social-democracia; a segunda - Horkheimer tem em mente, muito provavelmente, a Crítica ao programa de Gotha - é que Nietzsche acabou por avaliar equivocadamente o caráter histórico do trabalho, ao pensar que o trabalho não poderia perder seu efeito escravizador. Apesar de tudo isso, não se poderia deixar de reconhecer em Nietzsche "o ódio por um mundo dominado pela economia" (Chaves, 2010, pp.157-158).

Que pena Nietzsche não ter conhecido Marx... Os limites do pensamento burguês nietzschiano são agora como que deslocados para uma ausência de marxismo: seria ótimo Nietzsche corrigir seus desvios com a ajuda de Marx. Feito isso, sua análise da civilização poderia ter tomado um rumo certo, uma vez que era bem encaminhada e construída. Note-se agora a positividade (ainda revestida de um tom de censura, é certo) que se pode encontrar no pensamento de Nietzsche. Como já dissemos, bastará que esse modelo marxista de explicação da realidade social perca força para que o sentido mais amplo da crítica de Nietzsche venha à tona: poderíamos dizer que o Nietzsche de Horkheimer se torna mais "nietzschiano" à medida que aquela aposta no consórcio entre razão e crítica da economia política cai por terra no movimento em que as experiências acerca do socialismo passam a ser questionadas, por um lado, ao mesmo tempo em que os limites da racionalidade como mecanismo para a emancipação da sociedade ganham contornos mais decisivos, por outro. 0 resultado inevitável, a meu ver, para um leitor de Nietzsche, é perceber que sua filosofia busca se colocar justamente num local de crítica privilegiado, onde Marx e a racionalidade seriam presas fáceis. Dito de outro modo, tudo parece se passar como se o desenrolar do pensamento de Horkheimer o levasse cada vez mais ao encontro da filosofia de Nietzsche, na medida em que ela oferece um exemplo (que está longe de ser seguido em todos os seus resultados) de uma crítica que se pretende radical da razão - como indicou Habermas. $O$ fim da razão e $O$ estado autoritário são momentos iniciais desse processo - que, para ser analisado em um arco mais amplo exige, como observamos de início, uma investigação aprofundada das relações entre Horkheimer, Adorno e Benjamin (sem mencionar Pollock - e, talvez, Franz Neumann e seu Behemoth).

Sem pretensões de esgotar um texto como $O$ fim da razão, recolherei uma passagem - o primeiro parágrafo do texto - para indicar o quanto, em alguns aspectos, Horkheimer se aproxima mais de Nietzsche, sobretudo naquilo que diz respeito à sua crítica à razão - e, no mesmo movimento, à civilização.

Os conceitos fundamentais da civilização estão em processo de rápido decaimento. As gerações recentes não têm mais nenhuma confiança neles, e o fascismo tem 
reforçado suas suspeitas. A questão sobre até onde estes conceitos são afinal válidos clama por resposta mais do que nunca. O conceito decisivo entre eles seria o de razão, e a filosofia não conhece princípio mais alto. Ele foi suposto para ordenar os relacionamentos entre homens e para justificar todas as performances esperadas deles. Os padres da igreja e os espíritos orientadores do Esclarecimento concordam em seu louvor à razão (Horkheimer, 1993, p.26).

Essa passagem reflete a proximidade, nesse momento, entre a reflexão de Horkheimer e a filosofia de Nietzsche. Para este, o processo civilizatório é um resultado atingido também pelo modus operandi da razão na sua simbiose com a moralidade. Não é surpresa que o tema da moralidade também apareça com força no texto de Horkheimer - numa perspectiva, a meu ver, diferente da de Nietzsche. Nenhuma surpresa nisso, uma vez que Horkheimer reflete sobre a moralidade desde seus primeiros textos já em outro viés: se a moral - em Kant, por exemplo (cf. Materialismo e moral - in Horkheimer, 2006) - surge como um mecanismo para amortizar a desigualdade social economicamente produzida e percebida difusamente pela burguesia, em 0 fim da razão a moralidade perde sua possibilidade de existir, tragada pela perda da individualidade que o processo de autoconservação engendrado pelo esclarecimento impõe aos homens. Na única menção rápida a Nietzsche no texto, ele surge como aquele que anunciou a morte da moralidade: antecipa-se aqui, a meu ver, o realizador sem culpa do esclarecimento que Horkheimer e Adorno, anos depois, vão colocar num lugar central da Dialética do esclarecimento.

Também no já referido protocolo de discussão de 1942, feita a partir de um pequeno texto de Ludwig Marcuse sobre a relação entre carência (Bedürfnis) e cultura em Nietzsche, surge com Adorno e Horkheimer esta imagem de um Nietzsche crítico da civilização e da cultura. Participam da discussão Ludwig e Herbert Marcuse, Pollock, Günter Anders, Horkheimer, Adorno. Há no debate a meu ver, duas posições principais: de um lado há uma leitura que não vê convergência entre Nietzsche e Marx (posições, por exemplo, de Ludwig e Herbert Marcuse e Günter Anders) e que a meu ver dão, ao fim, razão a Marx; Adorno e Horkheimer, por outro lado, defendem uma confluência na análise de ambos, de modo que os dois autores passam como que a se completar (ou talvez, agora, Nietzsche “corrija” Marx):

Adorno: (...) A crítica da cultura de Nietzsche, apesar de suas categorias, identificou certos aspectos da problemática social que não foram dados per se na crítica da economia política. Ele desenvolveu certas intenções críticas mais além do que foram elaboradas na tradição pós-marxista. (...) L. Marcuse: Adorno busca salvar Nietzsche, na medida em que o coloca na fôrma marxista [indem er ihn über den marxisten Leisten schlägt]. Horkheimer: Adorno quer dizer que a expressão que certas estruturas assumem em Nietzsche não é um mero reflexo mas apresenta algo essencial (Horkheimer, 1987-1996, Band 12, pp.566 e 567). 
Bem, esse pequeno trecho do debate dá uma amostra do fato de que Adorno e Horkheimer têm, nessa época, uma posição parecida sobre Nietzsche, que surge como um crítico da civilização e da cultura a ser levado a sério, inclusive por acrescentar aspectos em sua análise que não se encontram na tradição pós-marxista.

Estamos, assim, um tanto distantes daquela posição que atestava em Nietzsche uma espécie de burguês ora ingênuo, ora perspicaz. Agora, na virada dos anos 1940, o quadro da filosofia de Nietzsche para Horkheimer é outro, como procuramos mostrar. O quanto esta transformação foi determinada pela colaboração com Adorno, é algo que não se decide aqui, dados, como dissemos de início, os limites deste artigo. Pergunta que, talvez, não consiga ser respondida precisamente, pois os textos tanto de Horkheimer quanto de Adorno não parecem oferecer a possibilidade de uma conclusão exata sobre a questão. Mas seja qual for a solução para isso, o fato é que se encontram presentes na obra de Horkheimer até a virada dos anos 1940 elementos suficientes não só para perceber um percurso onde muda o status da filosofia de Nietzsche como também para reconhecer - eis a ideia que subjaz a este artigo - que é absolutamente plausível que ele seja o autor principal do excurso II da Dialética do esclarecimento, como nos informa Habermas. ${ }^{4}$

\section{Referências}

Arato, A. e Gebhardt, E. (orgs.). (1993). The essential Frankfurt School reader. New York: Continuum.

Chaves, E., (2010) “Não se pode falar de Nietzsche, sem relacioná-lo claramente à atualidade". O Nietzsche "francês" nas páginas da Zeitschrift für Sozialforschung. Cadernos de Filosofia Alemã , 16, pp.147-165.

Habermas, J. (1986). „Bemerkungen zur Entwicklunggeschichte des Horkheimerschen Werkes“. In: Schmidt, A. \& Altwicker, N. (orgs.) Max Horkheimer heute: Werk und Wirkung. Frankfurt am Main: Fischer.

- (s/d.). Textos e contextos. Tradução de Sandra Luippert Vieira. Lisboa: Instituto Piaget.

(2007). Observações sobre o desenvolvimento da obra de Max Horkheimer. Tradução de Maurício Chiarello. Educação e Filosofia, 21(42), pp.273-293.

Horkheimer, M, (1987 - 1996). Gesammelte Schriften. 19 Bände. Frankfurt am Main: Fischer.

\footnotetext{
4 Cf. Habermas, 2007, p.284: "Além do mais, o jovem Adorno tinha tomado dois motivos de Benjamin: de um lado, a totalidade negativa e a história da natureza; de outro, a afinidade entre mito e modernidade. Na Dialética do Esclarecimento, eles se conectam com a ideia horkheimeriana de uma razão reduzida à função de autoconservação. Contudo, este texto não se apresenta absolutamente como um tecido inconsútil. A autoria de cada um dos capítulos não é a mesma de forma alguma. Gretel Adorno confirmou para mim, na ocasião, a suspeita que toma o leitor meticuloso: o ensaiotítulo e o capítulo sobre Sade remontam, na sua maior parte, à Horkheimer; os capítulos sobre Ulisses e sobre a indústria cultural remontam, em primeira linha, à Adorno. Não se trata aqui de uma diferença de cunho meramente estilístico".
} 
. (1993). "The end of reason". In: Arato, A. e Gebhardt, E. (orgs.). The essential Frankfurt School reader. New York: Continuum.

Perspectiva.

(2006). Teoria crítica I. Tradução de Hilde Cohn. São Paulo: Editora

Nietzsche, F. (1988). Kritische Studienausgabe. Vol. 10. Berlin: Walter de Gruyter.

Reijen, W., Noerr, G. (orgs.). (1987). Vierzig Jahre Flaschenpost: Dialetik der Aufklärung 1947 bis 1987. Frankfurt am Main: Fischer.

Wiggershaus, R. (2002). A escola de Frankfurt. História, desenvolvimento teórico, significação política. Tradução de Lilyane Deroche-Gurgel e Vera de Azambuja Harvey. Rio de Janeiro: Difel.

Recebido em: 03.03.2017

Aceito em: 02.06.2017 